To cite: Derby S, Forshaw M, Lowrie C, et al. Single modality radical radiotherapy is an acceptable alternative for the older patient with squamous cell carcinoma of the oesophagus. BMJ Open Gastro 2021;8:e000492. doi:10.1136/ bmjgast-2020-000492

Received 9 September 2020 Revised 1 December 2020 Accepted 20 December 2020
Check for updates

(C) Author(s) (or their employer(s)) 2021. Re-use permitted under CC BY. Published by BMJ.

${ }^{1}$ Clinical Oncology, Beatson West of Scotland Cancer Centre, Glasgow, UK

${ }^{2}$ Institute of Cancer Sciences, University of Glasgow, Glasgow, UK

${ }^{3}$ Upper Gastrointestinal Surgery, Glasgow Royal Infirmary,

Glasgow, UK

${ }^{4}$ Biostatistics, University of Glasgow Institute of Health and Wellbeing, Glasgow, UK

Correspondence to Dr Sarah Derby; sarah.derby@glasgow.ac.uk

\title{
Single modality radical radiotherapy is an acceptable alternative for the older patient with squamous cell carcinoma of the oesophagus
}

\author{
Sarah Derby (D) , ${ }^{1,2}$ Matthew Forshaw, ${ }^{3}$ Caroline Lowrie, ${ }^{1}$ Derek Grose, ${ }^{1}$ \\ Husam Marashi, ${ }^{1}$ Philip McLoone, ${ }^{4}$ Christina Wilson, ${ }^{1}$ David McIntosh ${ }^{1}$
}

\section{ABSTRACT}

Background 0esophageal cancer remains a common cause of cancer mortality worldwide. Increasingly, oncology centres are treating an older population and comorbidities may preclude multimodality treatment with chemoradiotherapy (CRT). We review outcomes of radical radiotherapy (RT) in an older population treating squamous cell carcinoma (SCC) oesophagus.

Methods Patients over 65 years receiving RT for SCC oesophagus between 2013 and 2016 in the West of Scotland were identified. Kaplan-Meier and Coxregression analysis were used to compare overall survival (OS) between patients treated with radical RT and radical CRT.

Results There were 83 patients over 65 years treated with either RT ( $n=21)$ or CRT $(n=62)$. There was no significant difference in median OS between CRT versus RT (26.8 months vs 28.5 months, $p=0.92)$. All patients receiving RT completed their treatment whereas $11 \%$ of CRT patients did not complete treatment.

Conclusion Survival in this non-trial older patient group managed with CRT is comparable to that reported in previous trials. RT shows better than expected outcomes which may reflect developments in RT technique. This review supports $\mathrm{RT}$ as an alternative in older patients, unfit for concurrent treatment.

\section{BACKGROUND}

Oesophageal cancer is one of the most common causes of cancer death in the UK and worldwide. ${ }^{2}$ Radiotherapy (RT), with or without concurrent chemotherapy is an option for radical management in appropriate patients. ${ }^{1-3}$ With an ageing population it is increasingly common to offer a radical approach to the older patient. Over $40 \%$ of new cases are now patients aged 75 years or over. ${ }^{4}$ Squamous cell carcinoma (SCG) of the oesophagus is associated with risk factors such as smoking and alcohol and is less common than adenocarcinoma of the oesophagus which is increasing in incidence. Management between adenocarcinoma and SCC of the oesophagus can differ. Non-surgical

\section{Summary box}

What is already known about this subject?

- Chemoradiotherapy (CRT) in squamous cell carcinoma (SCC) oesophagus is an effective radical treatment; however, older populations may not be fit for radical CRT.

What are the new findings?

- Radiotherapy (RT) can have comparable survival in older patients, unfit for concurrent chemotherapy.

How might it impact on clinical practice in the foreseeable future?

- RT should be considered as an acceptable alternative for SCC oesophagus in those unfit for chemotherapy.

treatment with radical RT or chemoradiotherapy (CRT) in SCC is accepted as an appropriate treatment strategy. ${ }^{5-8}$ While the incidence of squamous carcinoma of the oesophagus has been declining in recent years, it remains an important proportion of the population referred for treatment. Worldwide, SCC still accounts for $90 \%$ of oesophageal cancers; however, western countries have shown decline in recent years such as in the USA. Between 1975 and 2001 SCC oesophagus dropped from 31 per million to 19 per million whereas adenocarcinoma conversely increased from 3.8 to 23.3 per million in the same timeframe..$^{9}$ As the population of patients with cancer ages there will be an increasing challenge in managing older patients with SCC oesophagus. ${ }^{11} 12$

We report the experience of a large tertiary cancer centre treating SCC of the oesophagus with RT alone as an alternative in those patients not deemed fit for concurrent chemotherapy or where chemotherapy is contraindicated due to performance status (PS), comorbidity or patient preference. 


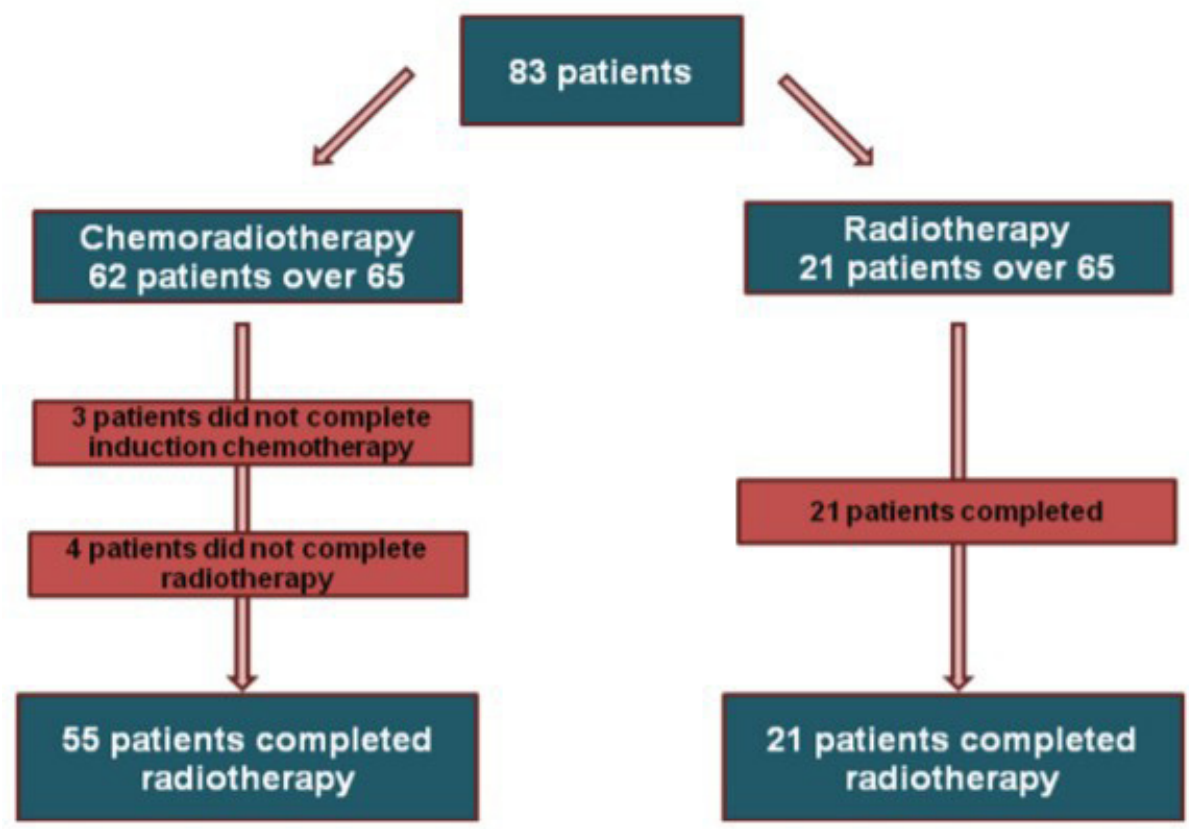

Figure 1 An outline of patient selection and completion of treatment for all patients treated between 2013 and 2016.

This centre has previously published favourable data on outcomes of radical RT for SCC oesophagus. ${ }^{13}$ Here, a review of the over 65 population is specifically addressed.

\section{METHODS}

\section{Study design}

This was a retrospective review of patients with SCC who were radically treated between March 2013 and March 2016 in the Beatson West of Scotland Cancer Centre, looking at PS, tumour, node, metastases (TNM) 7 staging, tumour length and treatment length along with survival of patients. ${ }^{14}$ Patients underwent endoscopic ultrasound (EUS), CT and positron emission tomography (PET) as part of tumour staging. Data were collected using electronic patient records and appropriate ethical permissions were obtained. Patients were analysed on an intention to treat basis (see figure 1). Tumour length was measured from ECLIPSE RT planning software using the gross tumour volume (GTV) from peer-reviewed RT plans. All plans were peer-reviewed at the volume assessment meeting with between two and five site-specialist consultants assessing each volume. The study team chose to use GTV length as a surrogate for tumour length as it was available for all patients. The tumour length was not always clearly documented from the diagnostic imaging or EUS, particularly in impassable tumours. EUS report, which traditionally includes anatomical landmarks and tumour length, as well as PET were central to the delineation of GTV contouring.

\section{Treatment}

There were 83 patients aged over 65 years identified: 21 received radical RT compared with 62 patients who had CRT during this period. Patients identified as receiving
CRT had chemotherapy concurrently prescribed. The chemotherapy regimen used in all patients was cisplatin $/ 5 \mathrm{FU}$ with an initial induction cycle followed by two concurrent cycles. Standard fractionation dose for the RT only group was the accelerated, hypofractionated 55 Gy in 20 fractions (RT 19/21 patients: other doses $52 \mathrm{~Gy} / 20 \#, 50 \mathrm{~Gy} / 25 \#)$. Standard RT fractionation for CRT patients was $50 \mathrm{~Gy}$ in 25 fractions (CRT 60/62 patients: other doses $54 \mathrm{~Gy} / 27 \#, 55 \mathrm{~Gy} / 20 \#$ prescribed). Standard of care for SCC oesophagus in this centre is CRT and surgery is only offered as a potential salvage option for persistent or relapsed disease.

\section{RT planning}

$\mathrm{RT}$ in this centre is delivered using intensity-modulated RT (IMRT) and more recently volumetric modulated arc therapy (VMAT) which can allow for improved conformality of RT dose and lower dose to organs at risk (OARs). Planning for these patients was a mix of IMRT 3 and 4 field RT planning with migration to a primarily VMAT solution in 2015. RT GTV was defined using composite information provided from EUS, CT and PET imaging. GTV was recorded from plans as a surrogate for tumour length in all patients. SCOPE-1 RT protocol was used as standard for delineation of clinical target volumes and planning target volumes. ${ }^{15}$

\section{Statistical analysis}

The characteristics of patients receiving RT or CRT were summarised using medians or percentages as appropriate and mean in reporting age. Differences were identified using Wilcoxon rank-sum test or Pearson's $\chi^{2}$ test. Survival was calculated from date of diagnosis until date of death or censor date (September 2018). Overall 


\begin{tabular}{|c|c|c|c|c|}
\hline \multirow{2}{*}{$\begin{array}{l}\text { Characteristic } \\
\text { Patient details }\end{array}$} & \multirow{2}{*}{$\begin{array}{l}\text { No. of patients }(\%) \\
\text { All patients }(n=83)\end{array}$} & \multirow{2}{*}{$\begin{array}{l}\text { Chemoradiotherapy } \\
(n=62)\end{array}$} & \multirow[b]{2}{*}{ Radiotherapy $(n=21)$} & \multirow[b]{2}{*}{$P$ value } \\
\hline & & & & \\
\hline \multicolumn{5}{|l|}{ Age (years) } \\
\hline Mean (SD; range) & $74.3( \pm 5.36 ; 65-86)$ & $72.8( \pm 4.22 ; 65-83)$ & $79.0( \pm 5.71 ; 66-86)$ & \multirow{2}{*}{$\begin{array}{l}p=0.0001 \\
p \leq 0.0001\end{array}$} \\
\hline$>75(\%)$ & $38(45.8)$ & $21(33.9)$ & $17(80.9)$ & \\
\hline \multicolumn{5}{|l|}{ Gender } \\
\hline Male & $39(47.0)$ & $32(51.6)$ & 7 (33.3) & \multirow[t]{2}{*}{$p=0.147$} \\
\hline Female & $44(53.0)$ & $30(48.4)$ & $14(66.7)$ & \\
\hline \multicolumn{5}{|c|}{ ECOG performance status (PS) } \\
\hline PS 0 & $39(47.0)$ & $32(51.6)$ & 7 (33.3) & \multirow[t]{3}{*}{$p=0.001$} \\
\hline PS 1 & $37(44.6)$ & $29(46.8)$ & $8(38.1)$ & \\
\hline PS 2 & $7(8.4)$ & $1(1.61)$ & $6(28.6)$ & \\
\hline \multicolumn{5}{|l|}{ Overall stage TNM 8} \\
\hline Stage I & $6(7.2)$ & $5(8.1)$ & $1(4.8)$ & \multirow[t]{4}{*}{$p=0.485$} \\
\hline Stage II & $45(54.2)$ & $31(50.0)$ & $14(66.7)$ & \\
\hline Stage III & $30(36.14)$ & $24(38.71)$ & $6(28.57)$ & \\
\hline Unknown & $2(2.4)$ & $2(3.2)$ & - & \\
\hline \multicolumn{5}{|l|}{ GTV length } \\
\hline Median (cm) (SD; IQR) & $5.7( \pm 3.01 ; 4.1-8.25)$ & $6.2( \pm 3.28 ; 4.1-8.8)$ & $5.2( \pm 1.94 ; 4.1-6.5)$ & $p=0.281$ \\
\hline$\leq 6 \mathrm{~cm}$ & $41(49.4)$ & $29(46.8)$ & $12(57.1)$ & \\
\hline$>6 \mathrm{~cm}$ & 39 (46.99) & $30(48.8)^{\star}$ & $9(42.90)$ & $\mathrm{p}=0.532$ \\
\hline
\end{tabular}

Summary of patient characteristics, overall stage: by TNM 8 definition.

*Three GTV values unavailable in chemoradiotherapy group.

GTV, gross tumour volume; TNM, tumour, node, metastases.

survival (OS) was estimated using the Kaplan-Meier method. Univariable and multivariable analysis of differences in survival between patients classified by each of sex, Eastern Cooperative Oncology Group (ECOG) PS, stage, modality and GTV length were performed using log-rank tests and Cox-proportional hazards regression. All tests were two-sided and a $p$ value $<0.05$ was considered statistically significant. Analyses were carried out using STATA V.14 (Statacorp).

\section{RESULTS}

\section{Patient characteristics}

A total of 83 patients were included in the study (RT $n=21$, CRT $n=62$, see table 1 ). There was a greater percentage of female patients in the RT group compared with the CRT group (RT $66.7 \%$ vs CRT $48.4 \%$, see table 1). There was also a higher percentage of patients over 75 years old within the RT group (RT $80.9 \%$ vs CRT 33.9\%). In the RT group, $33.3 \%$ of patients were PS 0 and in the CRT group $51.6 \%$ patients were PS 0 . T and $\mathrm{N}$ staging was similar in both groups as was overall stage.

\section{Compliance}

Over 95\% ( $\mathrm{n}=60)$ of CRT patients were prescribed 50 Gy in 25 fractions and $90.5 \%(n=19)$ of RT patients were prescribed 55 Gy in 20 fractions.
There were seven patients in the CRT group that did not complete RT consisting of three patients that did not complete induction chemotherapy and so did not proceed to RT and four patients in the CRT group that started RT but did not complete the treatment course (figure 1). Reasons for CRT non-completion included oesophageal perforation, stroke and deterioration in PS. All 21 patients in the RT group completed treatment.

\section{Tumour lengths}

PET and EUS reports were used as part of the GTV RT planning process. Length of tumour was identified based on the length stated on either EUS, endoscopy or radiology reports. However, there were 18 patients that did not have a recorded length based on these investigations. The main reason for the missing data was the presence of impassable disease recorded on EUS in 11 patients. This resulted in the absence of a lower border being reported (CRT=9, RT=2). Therefore, GTV length identified on RT planning software was used as an alternative comparative marker to reported EUS length as a surrogate length across all patients to provide a standardised approach in measurement.

\section{Survival}

Median OS for all patients was 27.0 months $(95 \% \mathrm{CI}$ 20.7 to 37.1 ) calculated on an intention to treat basis. 

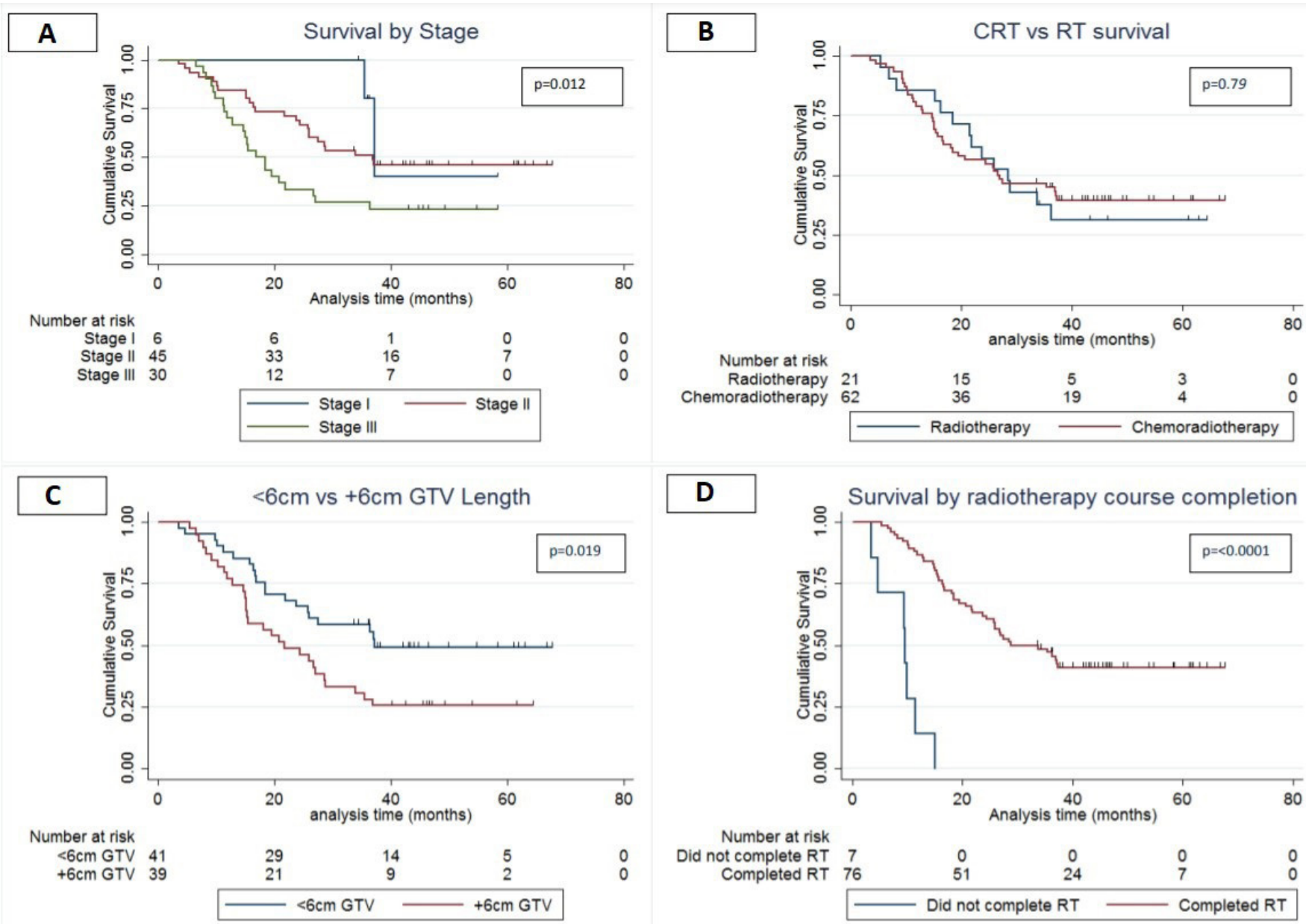

Figure 2 (A) Median overall survival (OS) stage I -37.3 months ( $95 \% \mathrm{Cl} 35.5$ to na), stage II $-37.0 \mathrm{months}$ (95\% Cl 25.7 to na), stage III-16.8 months (95\% Cl 12.83 to 26.7$)$; $p=0.012$. (B) Median OS radiotherapy (RT): 28.5 months (95\% Cl 20.7 to $37.1)$, chemoradiotherapy (CRT): 26.8 months $(95 \% \mathrm{Cl} 16.8$ to na); $\mathrm{p}=0.79$. (C) Median OS $<6 \mathrm{~cm}: 37.3 \mathrm{months}(95 \% \mathrm{Cl} 23.8$ to na), $\geq 6 \mathrm{~cm}$ : 21.6 months $(95 \% \mathrm{Cl} 15.1$ to 28.8$) ; \mathrm{p}=0.019$. (D) Median OS completed treatment $=28.8 \mathrm{months}(95 \% \mathrm{Cl} 23.8$ to na), did not complete treatment $=9.53$ months $(95 \% \mathrm{Cl} 3.53$ to 11.4$) ; \mathrm{p} \leq 0.0001$; na=unableto calculate $\mathrm{Cl}$ limit. GTV, gross tumour volume.

When divided into cancer stage, patients with early stage cancers had better survival than late stage cancers (stage $\mathrm{I}=37.3$ months; $95 \%$ CI 35.5 to na vs stage $\mathrm{III}=16.8$ months; $95 \%$ CI 12.83 to $26.7 ; \mathrm{p}=0.02$, see figure $2 \mathrm{~A}$ ). However, there was no statistically significant difference in median OS between the RT and CRT group (RT 28.5 months $95 \%$ CI 16.8 to na, CRT 26.7 months; $95 \%$ CI 18.4 to na, $\mathrm{p}=0.79$, see figure $2 \mathrm{~B}$ ). There was a non-significant increased risk of death in the male population versus females (male: HR 1.17; 95\% CI 0.66 to 2.10 ; $\mathrm{p}=0.574$ ). Patients with GTV lengths of $\geq 6 \mathrm{~cm}$ had a greater risk of death irrespective of treatment modality (HR for $\geq 6 \mathrm{~cm}-1.86, \mathrm{p}=0.041$, see figure $2 \mathrm{C}$, table 2 ). Patients with a PS of $\geq 1$ and stage III disease were also associated with poorer outcomes, though stage III disease was nonsignificant in multivariable analysis (HR for PS $\geq 1-2.11$, $\mathrm{p}=0.020$, HR for stage III disease-3.18, $\mathrm{p}=0.126$, see figure $2 \mathrm{~A}$, table 2 ).

Patients who did not complete planned RT had significantly poorer survival than patients who completed treatment (9.5 months vs 28.8 months figure $2 \mathrm{D}, \mathrm{p} \leq 0.0001)$.
Mean age for patients completing treatment and not completing treatment was 74.1 ( $\mathrm{SD} \pm 4.34$; range $66.7-$ 77.9 ) and 74.4 ( $\mathrm{SD} \pm 5.47$; range 65.5-86.2).

\section{DISCUSSION}

In this retrospective study focussing on data from 2013 to 2016 in the Beatson West of Scotland Cancer Centre we found that most of the RT group were over 75 years $(80.9 \%)$ compared with a significantly younger CRT group (mean age $=72.8$ years, percentage over $75=33.9 \%, p=0.0001)$. The difference in survival between sexes was non-significant although trended towards an increased risk of death in the male population. This may warrant future investigation in the context of the higher percentage of females in the RT group. Though the numbers are relatively small, this higher percentage should also be considered when looking at the relatively good survival of the RT group as improved survival in older women has been seen in other cancers such in lung cancer. ${ }^{16-19}$ There was no significant difference in 


\begin{tabular}{|c|c|c|c|c|c|c|}
\hline Patient characteristics & Unadjusted HR & $95 \% \mathbf{C l}$ & $P$ value & Fully adjusted HR & $95 \% \mathbf{C l}$ & $P$ value \\
\hline Female & 1 & & & 1 & & \\
\hline Male & 1.13 & 0.65 to 1.96 & $p=0.656$ & 1.17 & 0.66 to 2.10 & $p=0.574$ \\
\hline PS 0 & 1 & & & 1 & & \\
\hline$P S \geq 1$ & 2.00 & 1.14 to 3.53 & $p=0.016$ & 2.11 & 1.12 to 3.97 & $p=0.020$ \\
\hline Stage I & 1 & & & 1 & & \\
\hline Stage II & 2.07 & 0.49 to 8.79 & $p=0.326$ & 1.55 & 0.35 to 6.79 & $p=0.563$ \\
\hline Stage III & 4.31 & 1.01 to 18.35 & $\mathrm{p}=0.050$ & 3.18 & 0.72 to 14.00 & $p=0.126$ \\
\hline Radiotherapy & 1 & & & 1 & & \\
\hline Chemoradiotherapy & 0.92 & 0.50 to 1.71 & $p=0.793$ & 0.88 & 0.45 to 1.72 & $p=0.708$ \\
\hline $\mathrm{GTV}<6 \mathrm{~cm}$ & 1 & & & 1 & & \\
\hline $\mathrm{GTV} \geq 6 \mathrm{~cm}$ & 1.96 & 11.0 to 3.47 & $p=0.021$ & 1.86 & 1.03 to 3.37 & $p=0.041$ \\
\hline
\end{tabular}

HRs by patient characteristics, treatment modality and gross tumour volume lengths.

GTV, gross tumour volume; PS, performance status.

median OS between CRT and RT groups (figure 2B). CRT median OS remains comparable with other centres and the SCOPE-1 data, which is reassuring on considering that this is an older, real world-population. ${ }^{20-22}$ As expected, poorer PS and longer tumours were all associated with poorer survival.

It is of interest that as part of this retrospective review that there is a disparity in ages between the CRT and RT group. Multiple clinical trials across numerous tumour types have demonstrated the risk of increased toxicity of combining chemotherapy with RT. ${ }^{23-26}$ The stark difference in age between RT and CRT groups may arise from a clinical concern about fitness for multimodality treatment as the older patient, while fit, may be physiologically frailer than a younger individual. This is often gestalt rather than based on objective measures. Geriatric assessment tools are an emerging field that will be important in determining objective rather than subjective assessment for suitability of concurrent treatment. ${ }^{27} 28$ Similarly, future clinical trials should aim to include older patients with robust assessment tools particularly as this particular subgroup is often underrepresented but is increasing in clinical relevance. ${ }^{29}$ This represents a larger discussion that remains ongoing in the oncology community when consider how to balance these issues where older patients have radically treatable cancers.

The survival of patients undergoing single modality RT is perhaps surprising given the historically low expectations for single modality RT patients. ${ }^{24}$ There may be several possible reasons for this. Historical RT fractionation was $64 \mathrm{~Gy}$ in 32 fractions compared with the hypofractionated dose of $55 \mathrm{~Gy}$ in 20 fractions used in this centre. ${ }^{31324}$ It may be that this is a biologically superior dose as the 4-week period of treatment may offset the risk of cell repopulation after 28 days. Survival in this review is comparable to other centres using hypofractionated single modality RT and shows favourable outcomes in this patient group. ${ }^{30}$ New treatment modalities such as VMAT allow for excellent dose homogeneity to tumours with effective tissue simulation to estimate doses to primary tumour and OARs. Finally, another consideration is that this may also be an indication of appropriate patient selection and a pragmatic approach to frailer patients. It appears that single modality RT may be safe and deliverable in an older population.

There were several impassable tumours in the CRT group $(n=9)$ which were included in the unrecorded tumour lengths. Of the 11 patients who had confirmed impassable tumours there were no long-term survivors after 3 years of follow-up. This may suggest that an impassable tumour on EUS or endoscopy is a negative prognostic indicator of outcome. Luminal tumour bulk is qualitatively recorded on investigation reports and it may be a factor that warrants future consideration.

Finally, in this cohort single modality RT was better tolerated compared with CRT. Completing treatment is an important priority for these patients and is reflected in the poorer outcomes of those not completing treatment in the CRT group. All patients in the RT group completed treatment compared with an $11 \%$ non-completion in the CRT group. This is comparable to non-completion rate in other centres and the SCOPE-1 trial which was around 10\%. ${ }^{13} 2022$ Palliative locally advanced oesophageal cancer survival is often challenging to estimate but may be expected to be between 6 and 9 months though not usually over a year. ${ }^{31}$ The survival of RT patients in this review certainly appears favourable compared with these palliative patients; however, the heterogeneity in these groups prevents direct comparison.

The major limitation is the retrospective nature of the study. Though this information can be applied more generally, the lack of prospective fitness assessment prohibits a more detailed assessment of this population's characteristics. PS is a relatively limited descriptor and does not holistically represent true patient fitness. ${ }^{27}$ Future prospective reviews should use comprehensive 
geriatric assessment tools which give fuller assessments of this population as these patients are often heterogeneous in fitness and comorbidity. ${ }^{32}$ Similarly, toxicity data were not collected for these patients and can bring a wellrounded view on patient outcomes both on treatment and beyond. This is also an important focus for future reviews, particularly in older patient groups where quality of life rather than length of survival may be of greater priority. Furthermore, another limitation is that we have used GTV rather than prospectively gathered data from EUS, PET and CT to estimate tumour length. PET and EUS reports are integral to RT planning and are a key aspect which must inform GTV contouring. ${ }^{33}$ We feel that using GTV still provides a fair estimate of tumour length and our robust peer review process aims to maintain consistency.

\section{CONCLUSIONS}

Data reviewed in this series confers comparable results to other centres with improvement on survival in single modality RT compared with results from historical data. Other tertiary cancer centres have also found that hypofractionated regimens can have favourable outcomes in patients not suitable for CRT. CRT should remain a standard of care in radical treatment of squamous oesophageal cancer in fit patients. This review supports the use of single modality RT as an alternative option for those who are not suitable for concurrent treatment and may allow a survival advantage over best supportive care in an older population.

Acknowledgements Many thanks to the West of Scotland, Upper Gastrointestinal Cancer Managed Clinical Network and the members who directed this review. Sincere thanks go to the University of Glasgow and the SCREDS (Scottish Clinical Research Excellence Development Scheme) clinical lectureship for the academic support and resources provided that have contributed to the writing and research involved in this review. Thank you also to the CRUK-TRACC (Cancer Research UK-Train and Retain Academic Cancer Clinicians: award reference C7932/A29706) for the research and development support as part of the University of Glasgow Clinical Research Fellowship Programme.

Contributors DM and MF planned this study. DM sought permissions from MCN for data collection. SD and CL reviewed the data collected. PMc advised on statistical analysis. MF, DG, HM, CW and DM reviewed the data analysis and written review. SD wrote this paper and submitted the review.

Funding The authors have not declared a specific grant for this research from any funding agency in the public, commercial or not-for-profit sectors.

Competing interests None declared.

Patient consent for publication Not required.

Provenance and peer review Not commissioned; externally peer reviewed.

Data availability statement No additional data is available for access. This was an house audit of regional data. No raw data available to be disseminated due to local data protection laws.

Supplemental material This content has been supplied by the author(s). It has not been vetted by BMJ Publishing Group Limited (BMJ) and may not have been peer-reviewed. Any opinions or recommendations discussed are solely those of the author(s) and are not endorsed by BMJ. BMJ disclaims all liability and responsibility arising from any reliance placed on the content. Where the content includes any translated material, BMJ does not warrant the accuracy and reliability of the translations (including but not limited to local regulations, clinical guidelines, terminology, drug names and drug dosages), and is not responsible for any error and/or omissions arising from translation and adaptation or otherwise.
Open access This is an open access article distributed in accordance with the Creative Commons Attribution 4.0 Unported (CC BY 4.0) license, which permits others to copy, redistribute, remix, transform and build upon this work for any purpose, provided the original work is properly cited, a link to the licence is given, and indication of whether changes were made. See: https://creativecommons.org/ licenses/by/4.0/.

ORCID iD

Sarah Derby http://orcid.org/0000-0003-0040-0410

\section{REFERENCES}

1 Cancer Research UK. Oesophageal cancer statistics 2017, 2017. Available: https://www.cancerresearchuk.org/health-professional/ cancer-statistics/statistics-by-cancer-type/oesophageal-cancer\# heading-One. [Accessed 30th Nov 2019].

2 Arnold M, Soerjomataram I, Ferlay J, et al. Global incidence of oesophageal cancer by histological subtype in 2012. Gut 2015;64:381-7.

3 Sykes AJ, Burt PA, Slevin NJ, et al. Radical radiotherapy for carcinoma of the oesophagus: an effective alternative to surgery. Radiother Oncol 1998;48): :15-21.

4 ISD Scotland Cancer statistics. Oesophageal cancer 2013-2017, 2018. Available: https://www.isdscotland.org/Health-Topics/Cancer/ Cancer-Statistics/Oesophagal/\#summary [Accessed cited 2019 30th November 2019].

5 Boniface MM, Wani SB, Schefter TE, et al. Multidisciplinary management for esophageal and gastric cancer. Cancer Manag Res 2016;8:39-44.

6 Lagergren J, Smyth E, Cunningham D, et al. Oesophageal cancer. Lancet 2017;390:2383-96.

7 Boustani J, Rivin Del Campo E, Blanc J, et al. Quality assurance of dose-escalated radiation therapy in a randomized trial for locally advanced oesophageal cancer. Int J Radiat Oncol Biol Phys 2019;105:329-37.

8 Bedenne L, Michel P, Bouché O, et al. Chemoradiation followed by surgery compared with chemoradiation alone in squamous cancer of the esophagus: FFCD 9102. J Clin Oncol 2007;25): :1160-8.

9 Castro C, Bosetti C, Malvezzi M, et al. Patterns and trends in esophageal cancer mortality and incidence in Europe (1980-2011) and predictions to 2015. Ann Oncol 2014;25): :283-90.

10 Pohl H, Welch HG. The role of overdiagnosis and reclassification in the marked increase of esophageal adenocarcinoma incidence. $J$ Natl Cancer Inst 2005;97): :142-6.

11 Berger NA, Savvides P, Koroukian SM, et al. Cancer in the elderly. Trans Am Clin Climatol Assoc 2006;117:147-55.

12 Offman J, Pesola F, Sasieni P. Trends and projections in adenocarcinoma and squamous cell carcinoma of the oesophagus in England from 1971 to 2037. Br J Cancer 2018;118): :1391-8.

13 Fulton BA, Gray J, McDonald A, et al. Single centre outcomes from definitive chemo-radiotherapy and single modality radiotherapy for locally advanced oesophageal cancer. J Gastrointest Oncol 2016;7): :166-72.

14 Hsu P-K, Chen H-S, Liu C-C, et al. Application of the eighth AJCC TNM staging system in patients with esophageal squamous cell carcinoma. Ann Thorac Surg 2018;105): :1516-22.

15 Hurt CN, Nixon LS, Griffiths GO, et al. Scope1: a randomised phase II/III multicentre clinical trial of definitive chemoradiation, with or without cetuximab, in carcinoma of the oesophagus. BMC Cancer 2011;11: :466.

16 Wisnivesky JP, Halm EA. Sex differences in lung cancer survival: do tumors behave differently in elderly women? J Clin Oncol 2007;25): :1705-12.

17 Jung K-W, Park S, Shin A, et al. Do female cancer patients display better survival rates compared with males? analysis of the Korean national registry data, 2005-2009. PLoS One 2012;7): :e52457.

18 Ferguson MK, Skosey C, Hoffman PC, et al. Sex-associated differences in presentation and survival in patients with lung cancer. J Clin Oncol 1990;8): :1402-7.

19 Johnson BE, Steinberg SM, Phelps R, et al. Female patients with small cell lung cancer live longer than male patients. Am J Med 1988;85): :194-6.

20 Yew LC, Lucas O, Van Griethuysen J, et al. Long-Term outcomes following definitive chemoradiation for squamous cell carcinoma (SCC) of the oesophagus: a ten-year retrospective analysis. Clin Oncol 2018;30:p. S6.

21 Lavin VJ, Mehta S, Sumra P, et al. Experience of definitive chemoradiation for oesophageal cancer within a large regional 
cancer treatment centre: improving outcomes and tolerability. Clin Oncol 2018;30): :650-7.

22 Crosby T, Hurt CN, Falk S, et al. Chemoradiotherapy with or without cetuximab in patients with oesophageal cancer (SCOPE1): a multicentre, phase $2 / 3$ randomised trial. Lancet Oncol 2013;14): :627-37.

23 Pignon J-P, le Maître A, Maillard E, et al. Meta-Analysis of chemotherapy in head and neck cancer (MACH-NC): an update on 93 randomised trials and 17,346 patients. Radiother Oncol 2009;92): :4-14.

24 Herskovic A, Martz K, al-Sarraf M, et al. Combined chemotherapy and radiotherapy compared with radiotherapy alone in patients with cancer of the esophagus. N Engl J Med 1992;326): :1593-8.

25 Byhardt RW, Scott C, Sause WT, et al. Response, toxicity, failure patterns, and survival in five radiation therapy Oncology Group (RTOG) trials of sequential and/or concurrent chemotherapy and radiotherapy for locally advanced non-small-cell carcinoma of the lung. Int J Radiat Oncol Biol Phys 1998;42): :469-78.

26 Haefner MF, Lang K, Krug D, et al. Prognostic factors, patterns of recurrence and toxicity for patients with esophageal cancer undergoing definitive radiotherapy or chemo-radiotherapy. J Radiat Res 2015;56): :742-9.
27 Simcock R, Wright J. Beyond performance status. Clin Oncol 2020;32): :553-61.

28 Puts MTE, Hardt J, Monette J, et al. Use of geriatric assessment for older adults in the oncology setting: a systematic review. JNCl: Journal of the National Cancer Institute 2012;104:1134-64.

29 Hurria A, Cirrincione CT, Muss HB, et al. Implementing a geriatric assessment in cooperative group clinical cancer trials: CALGB 360401. J Clin Oncol 2011;29): :1290-6.

30 Jones CM, Spencer K, Hitchen C, et al. Hypofractionated radiotherapy in oesophageal cancer for patients unfit for systemic therapy: a retrospective single-centre analysis. Clin Oncol 2019;31): :356-64.

31 Eldeeb H, El-Hadaad HA. Radiotherapy versus stenting in treating malignant dysphagia. J Gastrointest Oncol 2012;3): :322-5.

32 Decoster L, Van Puyvelde K, Mohile S, et al. Screening tools for multidimensional health problems warranting a geriatric assessment in older cancer patients: an update on SIOG recommendationst. Ann Oncol 2015;26): :288-300.

33 Foley KG, Morgan C, Roberts SA, et al. Impact of positron emission tomography and endoscopic ultrasound length of disease difference on treatment planning in patients with oesophageal cancer. Clin Oncol 2017;29): :760-6. 